\title{
Flight Control System Development and Flight Test Experience With the F-111 Mission Adaptive Wing Aircraft
}

Richard R. Larson

\section{LBRARY RUPY}

A19 131300

KANGLY RESEARCH CENTER

LIBRARY, NASA

HAMPTOH, VIRGIN!A 


\section{Flight Control System Development and Flight Test Experience With the F-111 Mission Adaptive Wing Aircraft}

Aichard R. I.arson

Ames Research Center, Dryden Flight Research Facility, Edwards, California

\section{NกSA}

National Aeronautics and

Space Administration

Ames Research Center

Dryden Flight Research Facility

Edwards, California 93523-5000 
FLIGHT CONTROL SYSTEM DEVELOPMENT AND

FLIGHT TEST EXPERIENCE WITH THE F-111

MISSION ADAPTIVE WING AIRCRAFT

\author{
Richard R. Larson* \\ NASA Ames Research Center \\ Dryden Flight Research Facility \\ Edwards, California
}

Abstract

The wing on the NASA F-111 transonic aircraft technology airplane was modified to provide flexible leading and trailing edge flaps. This wing is known as the mission adaptive wing (MAW) because aerodynamic efficiency can be maintained at all speeds. Unlike a conventional wing, the MAW has no spoilers, external flap hinges, or fairings to break the smooth contour. The leading edge flaps and three-segment trailing edge flaps are controlled by a redundant fly-by-wire control system that features a dual digital primary system architecture providing roll and symmetric commands to the MAW control surfaces. A segregated analog backup system is provided in the event of a primary system failure. This paper discusses the design, development, testing, qualification, and flight: test experience of the MAW primary and backup flight control systems.

\section{Nomenclature}

AFTI advanced fighter technology integration

AICS airborne instrumentation computer system

$A D C$ analog-to-digital converter

CCDU cross-channel display unit

CLIN left inboard flap command

CLLE left leading edge flap command

CLMID left midspan flap command

CLOUT left outboard flap command

CRIN right inboard flap command

CRLE right leading edge command

CRMID right midspan command

CROUT right outboard command

$C P \quad$ command processer

CPU central processing unit

CRC cyclic redundancy characters

CST combined systems test

DAC digital-to-analog converter

DDIU digital data interface unit

EPROM erasable programmable read-only memory

ॠAerospace Engineer.
FCEU flight control electronics unit

FCS flight control system

FMET failure modes and effects testing

GRBK ground roll brake

HiMAT highly maneuverable aircraft technology

INBD inboard flaps

INTIN inboard flaps integrator command

INTLE leading edge flaps integrator command

IVTMID midspan flaps integrator command

I VTOUT outboard flaps integrator cormand

I $/ 0$ input-output

KiSSTICK roll stick gearing gain

L: $\quad$ leading edge

LIM limiter

LVDT inear variable differential transducer

LWD $1 \mathrm{eft}$ wing down

MAW irission adaptive wing

Mi:P manual command program

P primary hydraulic system

PCM pulse-code modulation

PI)U cower drive unit

P.0 parallel input-output

PI.IN left inboard flap position

PI.LE left leading edge flap position

PIMID left midspan flap position

PI.OUT left outboard flap position

PFIN right inboard flap position

PFiLE right leading edge position

PRIMID right midspan position

PR.OUT right outboard position

PTDRIV preflight test driver 


$\begin{array}{ll}\text { QC } & \text { impact pressure } \\ \text { ROLCOM } & \text { roll command } \\ \text { ROM } & \text { read-only memory } \\ \text { R/T } & \text { rolling tail } \\ \text { RWD } & \text { right wing down } \\ \text { SDLC } & \text { synchronous data link control } \\ \text { SIO } & \text { serial input-output } \\ \text { SDC } & \text { synchro-to-digital converter } \\ \text { SYMCMD } & \text { symmetric command } \\ \text { TACT } & \text { transonic aircraft technology } \\ \text { TE } & \text { trailing edge } \\ \text { U } & \text { utility hydraulic system } \\ \triangle P & \text { differential hydraulic pressure } \\ & \text { between PDUs of a given surface } \\ & \text { Introduction }\end{array}$

The aerodynamic design of today's highperformance aircraft is a compromise between conflicting requirements. Performance requirements are generally formulated for a wide range of operating conditions; however, a fixed airfoil is suitable only for a very limited range of flight conditions. One solution to this problem is the use of a variable-camber mission adaptive wing (MAW). The airfoil geometry of the MAW can be reconfigured in flight to improve aerodynamic performance throughout the flight envelope. Dramatic improvements are predicted in payload range, maneuverability, and ride qualities.

The National Aeronautics and Space Administration (NASA) and the U. S. Air Force have established a joint advanced fighter technology integration (AFTI) program to demonstrate the MAW technology.1 The Boeing Military Aircraft Company was selected to modify the wing on the NASA F-111 transonic aircraft technology (TACT) research aircraft to incorporate flexible leading and trailing edge flaps. This airplane, known as the AFTI/ F-111 airplane (Fig. 1), is being flight tested by the NASA Ames Research Center at the Dryden Flight Research Facility. This vehicle was chosen because it afforded the best opportunity to investigate subsonic, transonic, and supersonic flight regimes for a wide range of wing sweeps $\left(16^{\circ}\right.$ to $\left.58^{\circ}\right)$ and maneuvering conditions.

The MAW features smooth, flexible, fiberglass panels for both the leading and trailing edge upper flap surfaces, as shown in Fig. 2. The lower surface panels form a sliding flush seal when the camber is set at the $10 \mathrm{w}$-speed configuration. The flap drive mechanism is contained within the wing, so the smooth contour is not disturbed. The original TACT/F-111 wing box is a thin airfoil design; therefore, the internal flap drive incorporates rotary actuators, torque tubes, gear boxes, and hydraulic motors, as shown in Fig. 3. The thickness ratio for the MAW at a $16^{\circ}$ sweep is 9.7 percent at the root and 5.4 percent at the wingtip.

This paper presents the design, development, and qualification of the MAW flight control systems and subsequent flight test experience.

\section{AFTI/F-111 Airplane Modifications}

It was neccessary to modify the TACT/F-111 airplane for the MAW features (Fig. 4), which include a single leading edge flap, three-segment trailing edge flap, two flight control electronics units (FCEU), interfaces to the original electrical and hydraulic systems, interfaces to certain original sensors, and new MAW sensors, cockpit panel, and battery. Details of the modifications are described in Ref. 2 .

The MAW flight control system (FCS) was added to control the MAW leading edge (LE) and trailing edge (TE) flaps. This system is isolated from the basic F-111 control system that controls the stabilon and rudder so that any problem developing from the MAW system will not affect the basic airplane. The MAW FCEUs each consist of a primary and a backup FCS and servo drive electronics. The primary system features dual-channel digital com.. puters. The LE and TE flaps can be trimmed symmetrically. Also, the midspan and outboard flaps: are used as rolling flaps to supplement the stabilon. The backup system is a dual-channel segregated analog system; it is designed as a "get-home" mode and does not have all the functions of the primary system.

Separate primary and backup servo electronic:s receive a command from whichever system is controlling the flaps (primary or backup). Four types of signals can be generated to the valve at each power drive unit (PDU): proportional (commands), block, bypass, and brake. Internal servo electronics functions include the limiting of surface rate, surface position, and valve current as well as failure detection testing.

\section{MAW System Hardware Description}

The basic MAW flap actuation system consists of hydraulic motor, gear reduction box, electric brake, rotary actuator, control module, and torque tube. The motor, gear box, servo control valve, and brake are housed in the compact PDU module. The thin airfoil section of the TACT wing necessitated this compact arrangement. There are two PDUs for each of the eight MAW flaps.

\section{Primary System}

The primary MAW FCS architecture is shown in Fig. 5. The partitioning is structured so that each primary channel ideally provides one-half of the torque to drive a MAW flap. The numbers at each end of the flaps represent a PDU number, and $P$ and $U$ indicate primary or utility hydraulic system, respectively. Channel 1 and channel 2 commands are wired to the PDUs driven by the primary and utility hydraulic systems, respectively. Both FCEUs receive a dedicated differential pressure $(\triangle P)$ and flap position linear variable differential tranducer (LVDT) for each flap. The two primary computer servo commands are compared by 
monitoring their $\Delta P$ torques at opposite ends of the same flap. The $\Delta P$ signal is generated by a hardware sensor that measures the hydraulic pressure for force fight between the PDUs on a given surface. If there is a large force fight, the flaps cannot be driven with one channel, and the system would downmode to backup. In addition, if one of the primary computers should fail, the system would donwmode to backup.

Force fights are minfmized by the use of two equalization loops: position error and pressure. The position error loop provides identical actuating error signals to both servo amplifiers; these error signals are introduced by unequal position commands or unequal position transducer outputs, or both, within a $2.6^{\circ}$ limit. The pressure equalization networks minimize the force fight between the two servo loops that arises because of the inherent servo valve driver amplifier offsets and the bias offset currents of the two servo valves.

\section{Backup System}

The backup FCS architecture is different than the primary, as shown in Fig. 6. No control is provided to the LE flaps from this system, because they are automatically braked. Backup system A drives both POUs of the left midspan and right outboard and the inner PDUs of the inboard flaps. Backup system B drives both PDUs of the left outboard and right midspan and the outer PDUs of the inboard flaps. The backup system has its own dedicated LVDTs. Note that the roll flaps have only one backup LVDT per surface. If a single backup channel falls, the brakes would be set for those flaps, and the remaining backup system would continue to drive its dedicated flaps.

Isolation of Primary and Backup Systems

The primary and backup hardware components are generally isolated from one another. For example, a MAW roll stick transducer was added to isolate the MAW roll control from the basic F-111 FCS rolIing tail and to provide independent roll inputs to the MAW primary and backup FCS. There are six MAW roll stick transducers (two primary and four backup). Each backup system receives two stick inputs. Input discrete redundancy includes four contacts; two of these discretes go to the primary system while a different set goes to each backup system.

\section{MAW Flight Control System Description}

The following sections provide a brief description of the cockpit functions, primary FCS block diagram, backup FCS functions and downmode logic, and fault monitoring.

\section{MAW Cockpit Functions}

The pilot interface to the control of the MAW flap surfaces is accomplished by the use of a flap switch, roll stick, control and display panel, wing sweep handle, and gun trigger switch. The MAW control and display panel is shown in Fig. 7 . This panel is used in conjunction with the roll stick and flap switch to control the various functions of the MAW flaps; the panel al so conveys status information and flap positions of the MAW system. Many of the lights and meters are color coded for quick backup partitioning reference. A detailed description of the primary MAW FCS is given in Ref. 3. A brief description of some of the manual MAW control functions follows.

SYSTEM switch - selects primary or backup MAW FCS

PRI FAILED RESET switch - resets the backup latch, which allows entry to the primary FCS

MAW CAUTION light - flashes for downmodes or problems in the backup system; can be reset

QC FAIL 1ight - lights if the impact pressure (QC) probes difference becomes too large; the FCS will fix the roll gain and TE deflection limits for this failure; can be reset if the difference is within the tolerance

FLAPS lights - HALF, FULL, GND ROLL, and FAIRED lights indicate the LE and TE flap command selection

BACKUP RESET - various backup fault monitors will set these lights; monitors can be reset if the fault conditions have cleared

Brake switches - switches are provided for the $L E$, $A$, INBD, and $B$ MAW flap pairs for a manual brake engagement; manually braking any TE flaps will al so cause a downmode to the backup system

MANUAL COMMAND PROGRAM switch - LE and TE flaps $c$ an be positioned to preprogrammed positions by using the manual command program (MCP) function; used in conjunction with the 12-position selector switch

RATE SELECT switch - allows symmetric slewing at three different rates: FAST ( $5 \mathrm{deg} / \mathrm{sec}$ ), NORM (1 deg $/ \mathrm{sec})$, and SLOW $(0.3 \mathrm{deg} / \mathrm{sec})$

ROLL TRIM switch - used to command asymmetric trim for the MAW roll surfaces (midspan and outboard); it has a limited authority of $\pm 2^{\circ}$ about the symmetric command

\section{TRIM RESET button - removes MAW roll trim}

INBD FAIR button - causes the inboard flaps to drive to a position of $1.8^{\circ}$ when the sweep lever is at the $26^{\circ}$ detent and the flap switch is in RETRACT

Slew switches - manual symmetric trim capability is provided with the LE, ALL, INBD, MID, and OUTBD switches for the LE and TE flaps

PREFLIGHT TEST switch - a MAW preflight test program can be executed only on the ground; this is an automated function to test the force fight monitors, the LE brake hardware latch, and the backup system hardware latch

Flap switch - a MAW flap switch located on the front cockpit panel can command the LE and TE flaps to three camber configurations: RETRACT $\left(5^{\circ} / 2^{\circ}\right)$, HALF $\left(15^{\circ} / 10^{\circ}\right)$, and FULL $\left(20^{\circ} / 18^{\circ}\right)$

Home command - gun trigger switch on either stick is used to command the LE and TE flaps to $0^{\circ}$ and $2^{\circ}$, respectively 


\section{Digital Primary Control System}

The digital primary control system is designed to manually trim the LE and TE flaps symmetrically and to compensate for the roll control loss due to the removal of the spoilers from the TACT wing. Figure 8 is a simplified block diagram of the MAW control system showing the roll and symmetric commands. Impact pressure (QC) signals from the nose boom (QCNOSE) and fuselage side probes (QCSIDE) are filtered to reduce noise and then averaged (yielding QCAVE) for use in scheduling the roll stick gearing gain (KRSTICK). A lead-lag filter is used in the stick input path (ROLLSTK) to quicken the roll response for the takeoff and 1 and configuration. The roll gain (RGAIN) of 1.95 provides $18.5^{\circ}$ of MAW roll authority.

The roll command (ROLCOM) is derived by summing the roll command from the stick with the roll trim (RWD erim or LWD trim). The MAW trim has a $\pm 2^{\circ}$ limit about the trim point. Trim commands are faded out either by pressing the trim reset switch (TRIM RES) or whenever the system goes to the backup mode.

Symmetric commands are derived by integrating the various ways of commanding symmetric flap motion. The symmetric slew discretes are shown in order of priority from left to right. The manual command program (MCP) has the lowest priority, the inboard flap fairing command (FAIR) has the highest.

The roll flap servo commands are derived by summing ROLCOM with the integrator inputs (INTMID and INTOUT). The TE flap deflection limits are scheduled with $Q C$ and are rate limited. The midspan and outboard flaps are rate limited at $40 \mathrm{deg} / \mathrm{sec}$, the inboard flaps at $30 \mathrm{deg} / \mathrm{sec}$, and the leading flaps at $10 \mathrm{deg} / \mathrm{sec}$. The primary commands track the positions whenever the system is in backup. For a transfer from backup to the primary system, the commands are faded from the present flap position too the new updated primary commands in $2 \mathrm{sec}$.

\section{Analog Backup Control System}

The backup system can symmetrically position the TE flaps in three positions only, and there is no trimming capability. There is no control of the LE flaps; they are automatically braked. The TE flap rate and authority limits are the same as those in the primary system. Additional functions provided in the backup system are the ability to set $A$, INBD, or $B$ trailing edge flap pairs. The system is partitioned into independent $A$ and $B$ analog controllers. This design allows for partial control after the failure of one of the backup channels. Details of the backup FCS are described in Ref. 4.

Transition logic is designed to suppress the flap command switching transients when the control is transferred from primary to backup. This is accomplished by driving first-order filters with the current flap positions. An example for a single surface is shown in Fig. 9. When control is transferred to the backup system, the outputs of these filters are switched so that they are connected to the summing junctions to provide the initial flap command. The initial roll command (ROLLCMD) and symmetric command (SYMCMD) are zero immediately after switching to the backup control. They are then faded to their requested values by 4-sec time-constant filters.

\section{Fault Monitoring}

Fault checking is performed continuously in both the primary and the backup FCS, so the pilot and ground observers know the health of the total MAW FCS. The pilot can reset a backup failure monitor while still flying in the primary system. If the system downmodes to backup with an existing monitor fault, the brakes will be automatically set on the faulty system.

Failure monitoring can be divided into those failures originating in either the primary or the backup systems. Primary system failures can be grouped into two categories: (1) stay in primary and (2) downmode to backup. The backup system failures can also be grouped into two categories: (1) do not set brakes, and (2) set any combination of $A, B$, or INBD brakes. These general failures are shown in Table 1. Each type of fault has its own distinct fail discrete. These fall flags are available in the cross-channel data and are telemetered to the ground station.

The primary FCS is designed to prevent a MAW surface hardover. If a single command disagreement between the two channels exists, the fault monitor will generate a downmode. The downmode could be the result of a software command error or an excessive $\Delta P$. It is conceivable that a hardover could be possible while the backup system is engaged, but this would require the loss of a backup feedback signal in the servo electronics (that is, a frozen or open backup LVDT). However, if the flaps are in RETRACT, fault detection testing would cause the brakes to be automatically set. The worst-case flap offset would be less than $12^{\circ}$. Single and double flap runaways have been studied extensively in the simulator; they are easily controlled with opposite roll stick.

\section{F1ight System Development}

The MAW flight system development progressed in several stages. A design was developed that satisfied boch mission research requirements and safety of flight. A dual digital primary and segregated analog backup FCS evolved. The programming task was evaluated, and the Zilog $28000 \mathrm{CPU}$ was selected. Future software and hardware expansion was allowed for in the design. Six flight computers based on the $28000 \mathrm{CPU}$ were designed and built for the AFTI/F-111. The cross-channel data communications utilized a 280 chip. Specification documents were developed for both the primary 3 and the backup systems. 4

\section{Simulation Development}

A piloted simulation was used extensively to develop and assess the MAW control system design. The MAW FCS software structure for the simulation was programmed in FORTRAN using the flow charts 
found in the software design description document. 5 The information found in Refs. 3 and 4 was also used. During this effort some logic errors and design deficiencies were discovered and corrected before any flight code was generated. A software version for the simulation of the backup system was also interfaced with the simulation. Fault detection and downmode logic was structured for the simulation to reflect the flight system as much as possible. A set of possible failure modes was developed for pilot training and assessment of the FCS design. The failure input modes for the simulation are shown in Table 2 .

The simulation revealed a pilot-induced oscillation tendency in the landing approach, particularly in turbulence and crosswind conditions. A lead-lag filter (Fig. 8) was added for the power approach condition, and the rolling flap rate limit had to be increased from 30 to $40 \mathrm{deg} / \mathrm{sec}$ to alleviate this problem. The roll rate increase was accomplished by a linkage change in the flap drive mechanism.

\section{Hardware Acceptance Tests}

The individual hardware components for both primary and backup FCEUs were tested in each box separately according to the procedures outlined in Ref. 6. Primary system hardware was tested by temporarily cross-connecting input-output (I/0) to itself. All the discrete converters, analog-todigital, digital-to-analog, and synchro-to-digital converters ( $D A C, A D C$, and $S D C$, respectively), were tested in this manner. The backup system functions, such as filters, limiters, and gain schedulers, were tested by temporarily connecting to the primary I/0. The primary I/0 was driven by a microcomputer that contained the semiautomatic test programs. The test programs contained operator and primary FCEU I $/ 0$ instructions with built in pass-fail criteria. Hard copies of the test results were obtained for all the FCEUs.

\section{Flight Software Development}

The flight software code was written in assembly language from flow charts that were developed from Ref. 3. Figure 10 gives an overview of the software structure.

The two FCEUs are synchronized to assure that the difference between the start times of their minor cycles is less than $70 \mu \mathrm{sec}$. The two processors exchange a sync message through the communication channel. The elapsed time between sending a sync message and receiving the other processor's sync message is measured; since the actual transmission time is known, it can be determined which processor is lagging. The faster processor adjusts the count in its timer to synchronize with the slower unit.

The input module commands the hardware $A D C$ and SOC to perform their conversion and then reads a 12-bit value for each. This module then converts these quantities to a two's complement, two-byte fixed-point word in engineering units for use by the other modules. The discrete bytes are unpacked and debounced so that the third consecutive one in a string is recognized as a state change.
The surface position annunciator module tests the MAW surface positions against several standard configurations and sends output discretes for lamp drivers to the MAW panel (HALF, FULL, GND ROLL, and FAIRED lights).

The mode logic module generates two discretes that are used by the servo command and command integrator modules to cause the execution of initialization routines. The conditions for setting one or both discretes are (1) returning from backup to the primary system, (2) resetting the leading edge brake, and (3) computer power-up.

The command module generates symmetric command input rates to the integrators in the command integrator module.

The preflight test module generates a force fight for each of the MAW flaps by commanding a bias in one channel only. The $\Delta P$ hardware monitors trigger a fault discrete after the threshold is exceeded. The LE and backup hardware 1 atches are al so tested.

The $Z 8000$ communications module exchanges data between the two FCEUs through the crosschannel data message for comparison purposes in failure detection. Each command processor (CP) has one $Z 8000$ and one $Z 80$ processor running in parallel and communicating with each other througr. two parallel input-output (PIO) devices, as shown in Fig. 11. The 28000 processes commands and sensor inputs during each minor cycle and stores the developed data in a buffer (M2) that is shared with the $\mathbf{Z 8 0}$ by a handshake procedure through the PIOs. The 280 copies this buffer into its dedicated memory (M1) while the 28000 also copies this buffer into its dedicated memory (M3) for use in the next iteration for comparison (by the failure detection module) with the data transmitted by the other CP. The 28000 then continues processing new input while the 280 starts feeding the transferrec. data at $180 \mathrm{kbits} / \mathrm{sec}$ to one channel of a serial input-output (SIO) data link for transmission to the other $C P$, while simultaneously receiving data transmitted by the other $C P$ through the $S 10$.

The format of the transmitted message is derived from the IBM synchronous data link control (SDLC) convention. The address field is used by the receiver to verify that the message is intended for it. Each of the Cyclic Redundancy Characters (CRCs) consists of eight redundancy bits generated by the SIO upon transmission and verified upon reception.

The roll module calculates a roll command from roll stick and MAW trim inputs. This command is added antisymmetrically in the servo command module to the symmetric commands of the outboard and. midspan flaps.

The command integrator module integrates the rate commands that are input to it from the command module to form position commands. These commands are sent to the servo command module.

The failure detection module performs the following functions: (1) compares all analog and selected discrete inputs and outputs of the local channel with those of the other channel; (2) com- 
pares PDU differential pressures for each MAW surface of the local channel with those of the other channel; (3) compares the left and right LE positions; (4) compares each MAW flap position with an ideal model; and (5) declares and logs fallures when the comparisons exceed difference thresholds or when failure signaling discretes have been set by other modules.

The butlt-in test module does an ongoing check sum test of read-only memory (ROM) while waiting for the real-time clock to signal the end of a $20-m s e c$ minor cycle.

The servo command module combines the position commands for all MAW surfaces from the command integrator module, the preflight test module, and the roll module. The roll module commands are summed only with the midspan and outboard flaps. The commands are also rate and position limited.

The output module converts and scales the output variables of the servo command module from their internal digital format to a nonlinear $D A C$ voltage command to compensate for LVDT linkage. This is done by computing an index from the command for looking up in a table.

\section{Flight Software Testing}

The flight software was tested in four phases: (1) individual module tests, (2) intermodule tests, (3) hot-bench open-loop tests, and (4) integrated airplane systems tests. The first two phases were done in a non-real-time batch mode that used a 28000 simulator computer; in the second two phases the software was running in the actual flight hardware computers.

The individual modules were coded by a programmer from flow charts that were developed from the software specification. The software verifier developed a flow chart from the code and compared this with the original flow chart for similarity. The 1/0 and all possible logic branches were tested by adding a loop around the function being tested to simulate a real-time execution. The contents of pertinent registers were printed for each iteration and compared with the expected values.

The intermodule tests checked the interface between the modules. The output of one module is used as an input to another. The entire set of modules was eventualiy integrated in this manner.

The hot-bench testing utilized the actual flight computers for the software verification. 7 The FCEUs were connected to a control panel that simulated the aircraft sensor interface. This was an open-10op system because the LVDT feedback signals were generated from hand pots. The test setup is shown in Fig. 12. The control and display panel and the aircraft sensors were wired to a control patch panel. This allowed the signals to be opened for checkout and fault testing. The MAW servo commands and other signals were hardwired to strip chart recorders. Also, a crosschannel display unit (CCDU) was used to access the cross-channel data message.

The CCDU is microprocessor-based ground support equipment that was developed specifically for the AFTI/F-111 program. The experience of using an earlier version of the CCDU on the highly maneuverable aircraft technology (HIMAT) program $^{8}$ prompted the decision to develop one for this program. The CCDU displays the digital data message in an engineering unit format on a CRT or sends signals out to 16 DACs for strip chart recordings. Basically, the CCDU maps the crosschannel data message from each computer into its own internal memory address. The data are then referenced symbolically by the use of a symbol table that divides the message into mnemonic names and byte lengths. The discrete bytes are unpacked for convenient user-oriented data displays. Hard copies of any CRT data display can also be made on a line printer. The structure of the crosschannel message is shown in Table 3 .

The CCDU proved to be a valuable tool in debugging problems and verifying the software in general. Even if a desired byte or bytes were not on the cross-channel message, a temporary change to the message could be made without making a new erasable programmable ROM (EPROM). This change would be made by stopping an FCEU from the terminal and entering the addresses of the desired bytes (up to 18) in the WINDAT portion of the message. After both FCEU messages have been modified, they are started again in the realtime run mode. The default WINDAT addresses remain overwritten until the power on the FCEUs is cycled. The CCDU operator can redefine data lengths in the WINDAT portion of the symbol table if necessary and then make any data type changes on the CRT displays.

\section{Flight Qualification}

The flight qualification tests were done on the airplane as a total integrated system. These tests were done in two phases: (1) testing performed in the hangar and (2) engine run tests. The hangar testing used an external hydraulic supply system that did not have the flow rate capability of the engine pumps.

\section{Hangar testing}

The test setup for the hangar testing is depicted Fig. 13. Three means of testing and trouble shooting the FCEUs were utilized: the CCDU, breakout boxes, and extender cards. The CCDU provided read-only access of each FCEU crosschannel data message in user display formats. This provided a versatile tool during the qualification tests and for trouble shooting problems. Breakout boxes, required for certain types of testing, were inserted between the aircraft $1 / 0$ connections and the FCEUs. Access to the external FCEU I $/ 0$ signals was accomplished through these boxes. These boxes were utilized to monitor, open, and insert voltages for the failing modes and effects testing (FMET) and for troubleshooting test modes. Extender cards were used as a last resort because they involved opening an FCEU box, removing the desired card, and putting it on an extender.

A detailed test plan procedure ${ }^{9}$ was developed for these systems tests. The major tests are listed in Table 4 . During the process of performing these tests a number of hardware and 
software anomalies and design errors were discovered. They were not discovered earlier, because the FCEUs had never been interfaced with a real aircraft system. A number of changes to the MAW FCS hardware and software were made to correct the anomalies. The piloted simulation was used to test any proposed FCEU changes that might affect the flying qualities.

\section{Engine runs}

The engine run tests provided a total functional check of the system in the real environment of actual hydraulic and electrical power generated from the engines. One of the major tests was to deternine during what conditions the hydraulic capability was marginal. Continued stick cycling, particularly for single-engine operation, showed less than desirable safety margins. Also, fault monitors in both the primary and backup MAW FCS were set because of the slower flap rates. Further hardware and software changes were made to improve the flap positions predictor and to disable the downmode logic for critical flap positions during landing. The hydraulic pump flow rate capacities were also upgraded by 10 percent.

\section{Real-Time Monitoring}

The AFTI/F-111 airplane is extensively instrumented. The signals are recorded in pulse code modulation (PCM) format to an on-board tape and are also telemetered to a ground station for realtime monitoring. A portion of the FCEU crosschannel message ( 78 bytes) is interfaced with the PCM instrumentation system through a digital data interface unit (DDIU) and an airborne instrumentation computer system (AICS). The DDIUl0 receives serial data streams at 50 samples/sec from each FCEU. The DDIU transmits a 16-bit parallel data word composed of 8 bits of label (HI byte) and 8 bits of data (LO byte). The AICS is programmed to test for a particular label byte followed by its data byte. If the data are coming in too fast or if the label bytes are not in ascending order. fault flags are issued on the PCM downlink.

The control room real-time monitoring includes the various types of CRT displays (color panel, color graphics, and data). A number of strip charts are also used. The color panel display that shows the MAW status and faults is shown in Fig. 14. The color panel is used to display the following types of information:

1. Annunciatior lights of the MAW control and display panel

2. Error flags from each FCEU

3. Indicators that signify "good" data are being received

4. Certain airplane system status information that affects safety of flight

5. Automatic piloted procedure requests depending on particular fault conditions

6. Wing sweep fault testing

7. Preflight test counter information

Latches are created in the control room computer on any faults that would cause a backup downmode or set a status light. The intent is to deterinine immediately the cause of any problem. An audio cue (three tones) is provided in the con- trol room whenever the MAW CAUTION light starts to flash. The fault latch is dropped when the pilot resets the MAW CAUTION light or when the FCS engineer resets the latch flag using a keyboard in the control room.

The real-time software verification testing was done in three phases: (1) external signal simulation into the ground station computer; (2) generation of real PCM signals by hard-wiring to the airplane from the hangar; and (3) actual telemetry transmission from the airplane at the engine run area for combined systems tests (CST). The first phase tested the driver logic for the realtime displays, while the second phase tested the PCM interface to the computer. The third phase tested the path from the airplane antenna to the ground station receiver to the computer interface and also tested for any signal interference during the data transmission.

\section{Flight Test Experience}

Most of the MAW FCS signals are available on the telemetry downlink, thus providing the capability of making real-time judgments based on this information. A MAW system failure decision tree (Fig. 15) was developed to establish procedures in the event of MAW problems during flight. Basically, the pllot wants a simple procedure for any MAW failure indication; the established procedure is to brake all the MAW flaps in their current position and await instructions from the ground station. The flight controls engineer can determine the nature of the anomaly from the MAW status and faults color panel and other displays and then advise the pilot to release the brakes and to attempt to reset the failure or to land with the MAW flaps braked and use only the stabilions for roll control.

To date, there have been a total of four flights of the AFTI/F-111 MAW aircraft. The MAW FCS has been fully engaged for all takeoffs and landings. Most of the MAW primary FCS functions have been demonstrated in flight. Also, the MAW backup FCS has been manually engaged at altitude for piloted evaluations; it has performed very well. All the MAW flaps have been manually braked for tail-only roll control evaluation. In this configuration the airplane is expected to be relatively easy to 1 and in the absence of other failures or excessive crosswinds.

An anomaly occurred after the second flight: The airplane failed to pass the automated MAW preflight test program function. Very rapid analysis of the problem using the CCDU and breakout boxes traced the problem to PDU number 4 , which is on the right outboard side of the right LE flap (see to Fig. 5). Inspection of the PDU revealed that it was uncoupled because of a sheared mechanical fuse link in the shaft between the motor and the gear box. All the LE PDU motor shafts were inspected and replaced.

One of the brakes in the left leading edge flap occasionally failed to release properly during ground test. A workaround procedure was developed for the first two flights. Both left LE brakes were replaced after the second flight. 
During the third flight a hydraulic leak occurred in the F-111 utility system, which caused the flight to be terminated early. The airplane was 1 anded without incident using the primary MAW FCS.

\section{Concluding Remarks}

The MAW FCS design development grew in scope and complexity from the original concept. The foremost consideration was flight safety, which required redundancy in both the primary and the backup systems. The second design consideration was the mission requirements. The lessons learned during the development process are outlined below.

1. The initial MAW design was tested early using pilot-in-the-loop simulations before any hardware procurements were initiated. This early assessment allowed changes to be made during iterations of the design process before concepts were frozen and changes became expensive.

2. The MAW FCS design allowed for hardware and software expansion, which was necessary to allow for modifications during the development and flight qualification process.

3. The simulation program was coded directly from the flight specification document. Errors in the software logic were found early and corrected, which saved time by eliminating these errors prior to the generation of flight software.

4. The thorough ground testing process proved to be an important element in finding and ultimately correcting anomalies so that the airplane could be qualified for flight test.

5. The sensors, commands, fail flags, and I/0 discretes, which were made accessable to the engineers through the cross-channel data message, proved very valuable in the FMET, trouble shooting test modes, and real-time monitoring during flight test. The problems most difficult to solve were those that involved data that were not on this bus.

6. The design of the MAW system made it easier to test and troubleshoot the system because of easy access to signals on the crosschannel data bus and hard-wired test points on the component cards back plane.

7. The decision to develop ground testing tools, particularly the CCDU and breakout boxes, before problems occurred saved considerable time and money in identifying problems during the flight qualification process.
8. Adding the DDIU so that the MAW crosschannel message was available by downlinking through the instrumentation system proved to be very important. This provided real-time monitoring capability of the MAW FCS and the establishment of piloted procedures based on the data analysis from the control room.

\section{References}

lDeCamp, R.W., and Hardy, R., "Mission Adaptive Wing Research Programme," Aircraft Eng., vol. 53, Jan. 1981, pp. 10,11.

2Hynes, R.J., "AFTI/F-111 MAW Manual Flight Control System Description," D365-10100-1, The Boeing Company, 1983.

3Logan, D., and Thomasson, R., "Software Requirements Specification for AFTI/F-111 MAW Manual Flight Control System," D365-10062-1, Revision L, The Boeing Company, 1985.

4Thomasson, R., "Requirements Specification for AFTI/F-111 MAW Backup Flight Control System," D365-10091-1, The Boeing Company, 1982.

5 Suh1, E., and Wagaman, J., "AFTI/F-111 Manual Control System Software Design Description," D365-10072-1, Revision E, The Boeing Company, 1981.

6Higinbotham, P., and Boldrin, C., "AFTI/ F-111 MAW FCS Electronics Functional Test Procecures (Flight Control Electronics Unit Acceptance Test)," D365-10061-3, The Boeing Company, 1981.

7Thomasson, R., "Computer Program Verification Tests for the Manual MAW System," D36510088-1, Revision B, The Boeing Company, 1984.

8Glover, Richard D., "Aircraft Interrogation and Display System: A Ground Support Equipment for Digital Flight Systems," NASA TM-81370; 1982.

9Boldrin, C., et al., "AFTI/F-111 MAW Flight Control System Test Procedures," D365-10060-2, Revision C, The Boeing Company, 1985.

10Aragon, A.L., "Digital Data Interface Unit (DDIU) Requirements Specification and Interface Definition (WBS-15000)," D365-10082-1, The Boeing Company, 1985. 
Table 1 Fault detection

\begin{tabular}{|c|c|}
\hline \multicolumn{2}{|l|}{ Primary failures } \\
\hline Failures not causing downmode & Failures causing downmode to backup \\
\hline $\begin{array}{l}\text { Any LE failure (system will set LE brakes) } \\
\text { QC probe (system will set fixed roll gain and TE limit) } \\
\text { Ideal model (LE and roll flaps) }\end{array}$ & $\begin{array}{l}\text { Command (except } L E \text { ) } \\
\text { Selected output discretes } \\
\text { Ideal model (inboard flaps only) } \\
\Delta P \\
\text { Stick } \\
\text { Power supply } \\
\text { Hydraulic pressure <1200 lb/in2 } \\
\text { Computer executive error } \\
\text { Watch dog timer }\end{array}$ \\
\hline \multicolumn{2}{|l|}{ Backup failures } \\
\hline Failures not causing brakes to be set & $\begin{array}{l}\text { res causing any combination of } A, B \text {, } \\
\text { or INBD brakes to be set }\end{array}$ \\
\hline $\begin{array}{l}\text { Aliveness monitor } \\
\text { OC (system will set fixed roll gain and TE limit) } \\
\text { Single hydraulics } \\
\text { Ideal model (flaps HALF/FULL) }\end{array}$ & $\begin{array}{l}\text { Valve current } \\
\text { Position limit } \\
\text { Power supply } \\
\text { Stick } \\
\text { Ideal model (flaps RETRACT) }\end{array}$ \\
\hline
\end{tabular}

Table 2 Simulation system failure inputs

MAW A flap roll hardover to the left
MAW A flap roll hardover to the right
MAW B flap roll hardover to the left
MAW B flap roll hardover to the right
Left LE brake set
QC fail
Single hydraulic system fail
Inboard flap fairing fault
Pitch damper fail
Roll damper fail
Yaw damper fail
S3 LE differential fail
A backup reset monitor
B backup reset monitor
INBD backup reset monitor
Engine fail
Downmode to backup
IDENT fault (roll reversal)
Model fault threshold

Table 3 Cross-channel data message

\begin{tabular}{lc}
\hline Signals & Length, bytes \\
\hline FLAG & 1 \\
ADDRESS & 1 \\
CONTROL & 1 \\
FRAME COUNT & 4 \\
ERROR FLAGS & 10 \\
INPUT DISCRETES & 14 \\
OUTPUT DISCRETES & 8 \\
D/A OUTPUTS & 24 \\
WINDAT & 18 \\
ANALOG INPUTS & 94 \\
\hline
\end{tabular}


Table 4 Qualification tests

$\begin{array}{ll}\text { Test prerequisites } & \text { Failure modes and effects testing } \\ \text { Continuity check of MAW FCS wiring } & \text { Hydraulic } \\ \text { Voltage check of MAW FCS wiring } & \text { Electrical } \\ \text { Test equipment calibration } & \text { LE differential } \\ \text { Flap calibration } & \text { Position } \\ \text { MAW flight control system tests } & \text { DP } \\ \text { Control and display panel lamp checks } & \text { Input discrete } \\ \text { Backup FCS validation } & \text { Output discrete } \\ \text { Primary-Backup transitions } & \text { Hysteresis tests } \\ \text { MAW brake engagements } & \text { Dynamic response tests } \\ \text { PDU bypass, block, brake } & \text { DDIU tests } \\ \text { Hydraulic bypass interlock } & \text { Piloted evaluations } \\ \text { MAW electrical system tests } & \text { Engine runs } \\ \text { MAW battery operation time } & \text { Combined system tests } \\ \text { Reduced voltage operation } & \text { FCS } \\ \text { Flap switch effects on the basic F-111 FC: } & \end{array}$

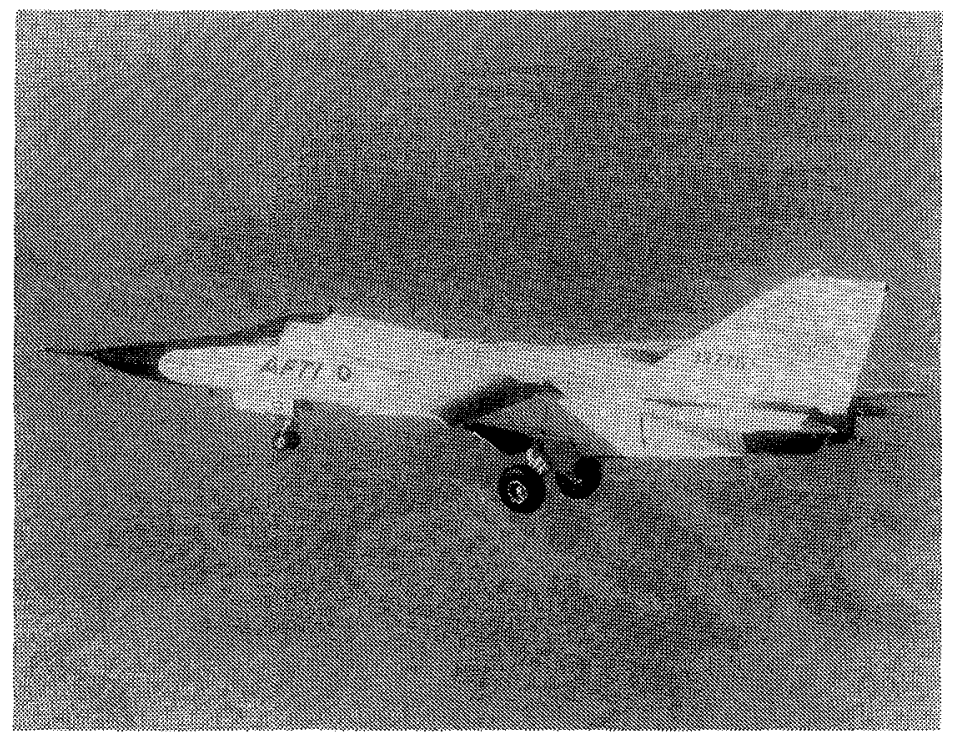

ECN 33205-011

Fig. 1 AFTI/F-111 airoraft. 


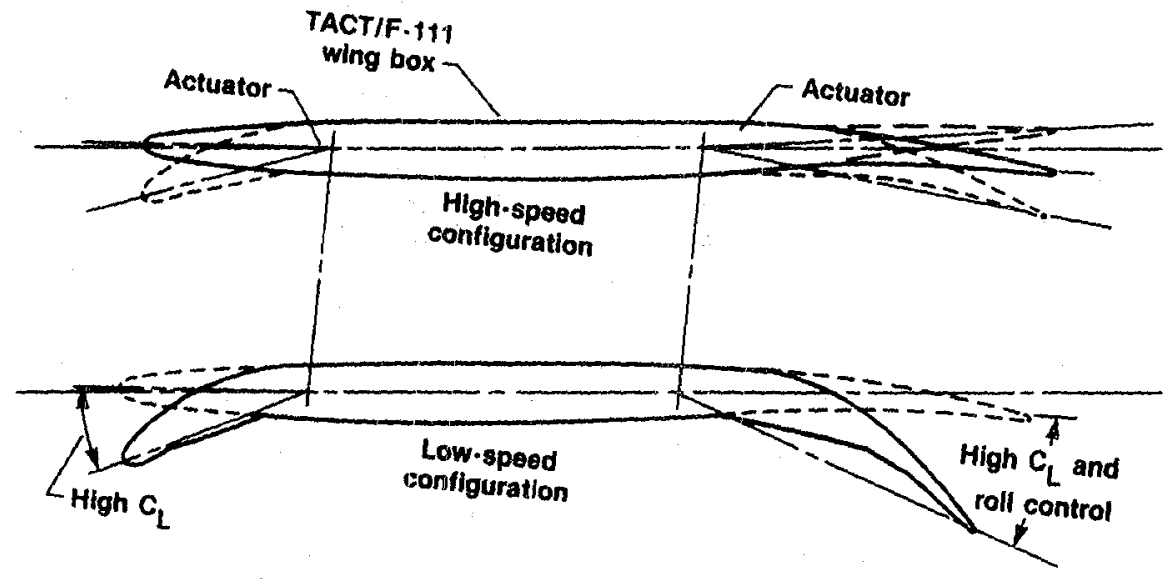

Fig. I Vamiable-camber surface movement.

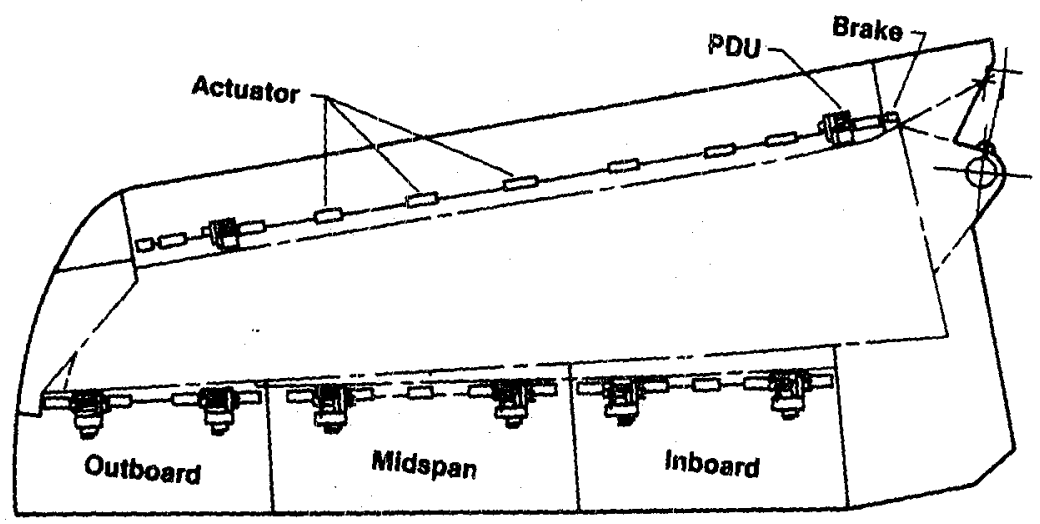

Fig. 3 AWTI/F-111 flap actuation syotem.

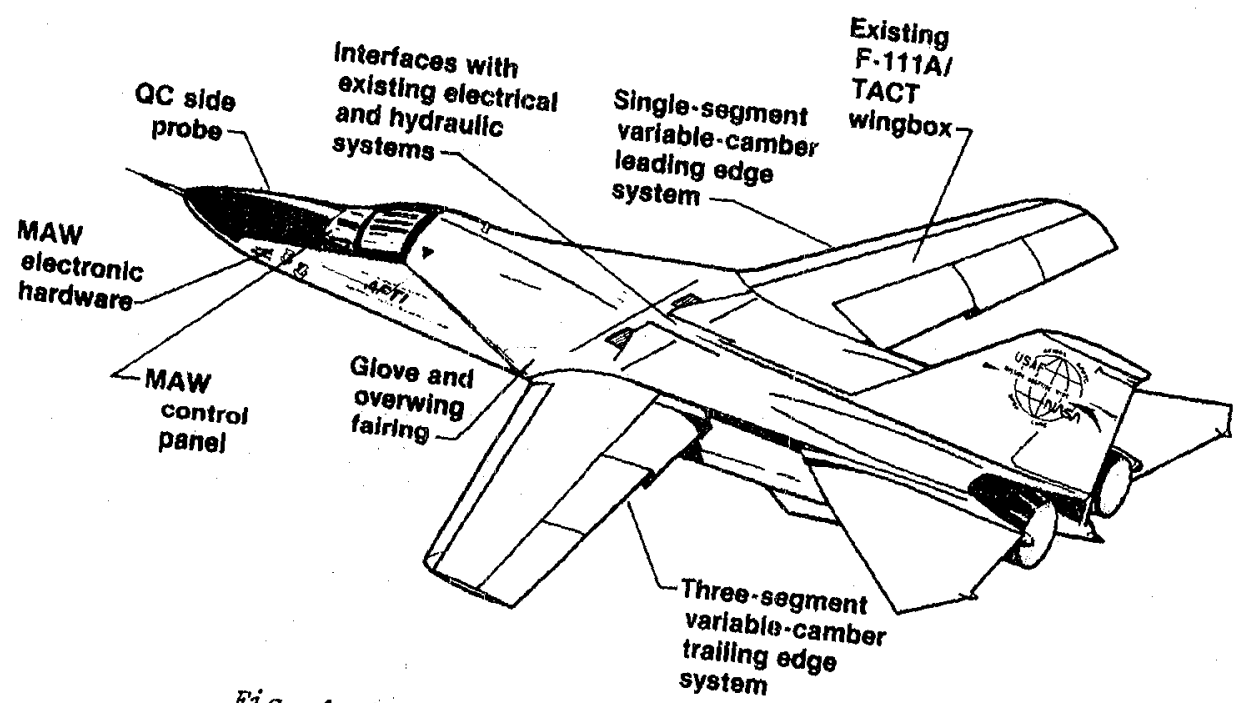

Fig. I AFTI/E-III principal modifications. 


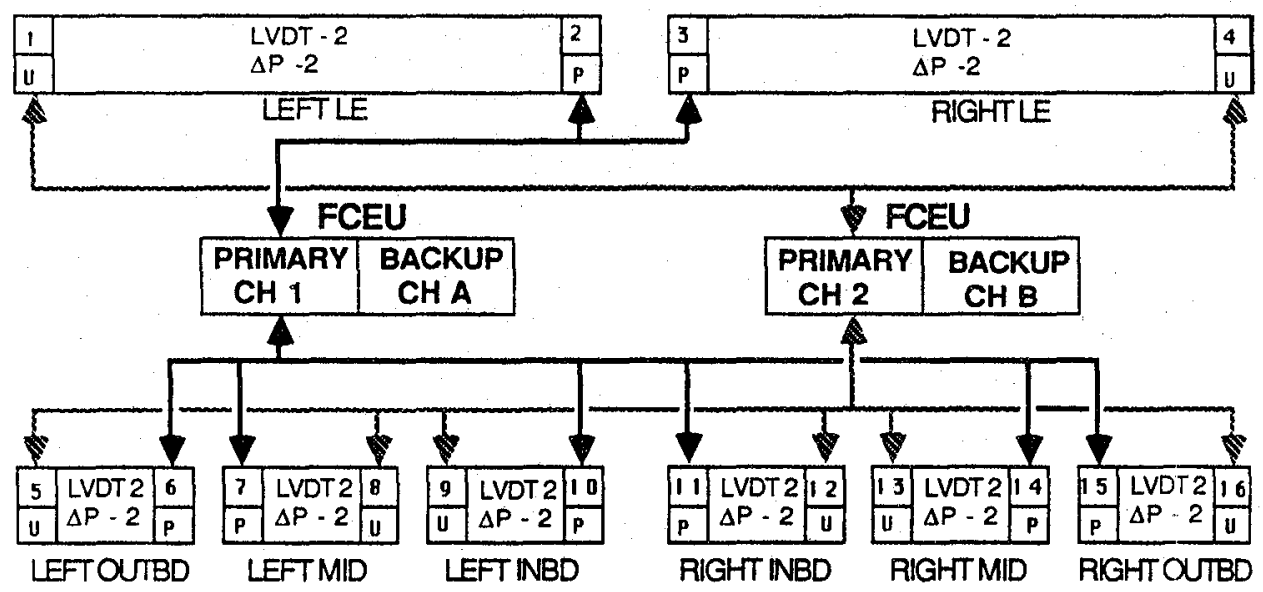

NOTES: (1) The signal flow is a two-way path: (2) No. - PDU number from FCEU - commands $\quad$ (3) $P$ - primary hydraulics to FCEU - $\triangle P$, LVDTS U - utility hydraulics

Fig. 5 system architecture of digital primary FCS.
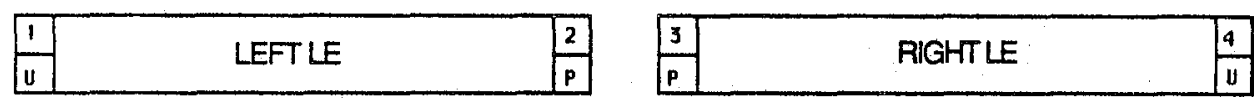

FCEU

\begin{tabular}{|l|l|}
\hline PRIMARY BACKUP & -1 \\
\hline
\end{tabular}

$\mathrm{CH} 1$ CH A
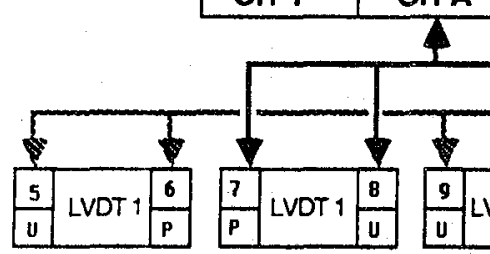

LEFTOUTBD LEFT MID

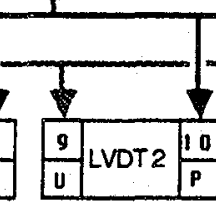

LEFT INBD
FCEU

\begin{tabular}{|c|c|}
\hline $\begin{array}{c}\text { PRIMARY } \\
\text { CH } 2\end{array}$ & $\begin{array}{c}\text { BACKUP } \\
\text { CH B }\end{array}$ \\
\hline
\end{tabular}

NOTES: (1) The signal flow is a two-way path: (2) No. - PDU number
from FCEU - commands
to FCEU - $\triangle P$, LVDT s
(3) $P$ - primary hydraulics
$\mathrm{U}$ - utility hydraulics

Fig. 6. System architecture of analog backup FCS. 


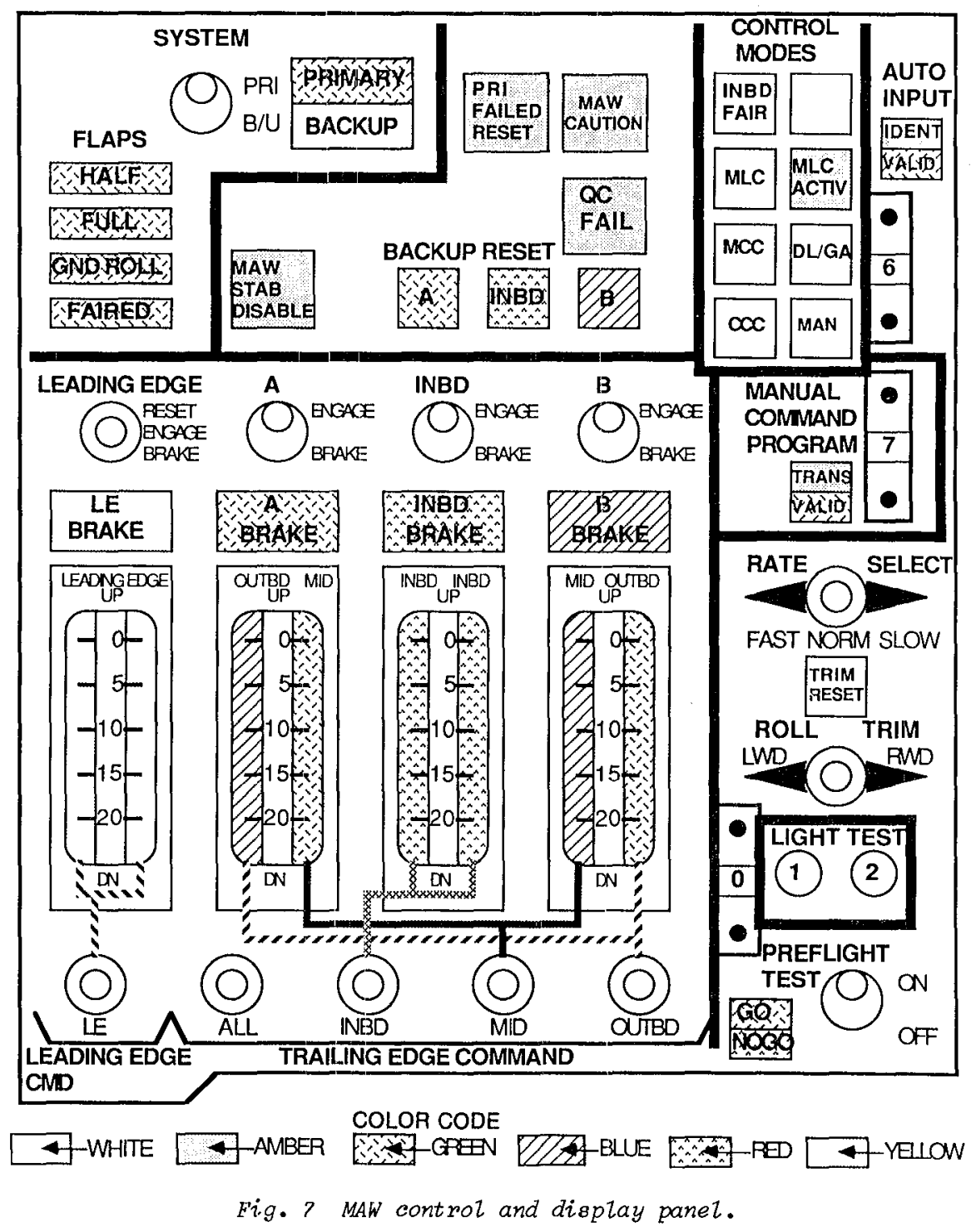



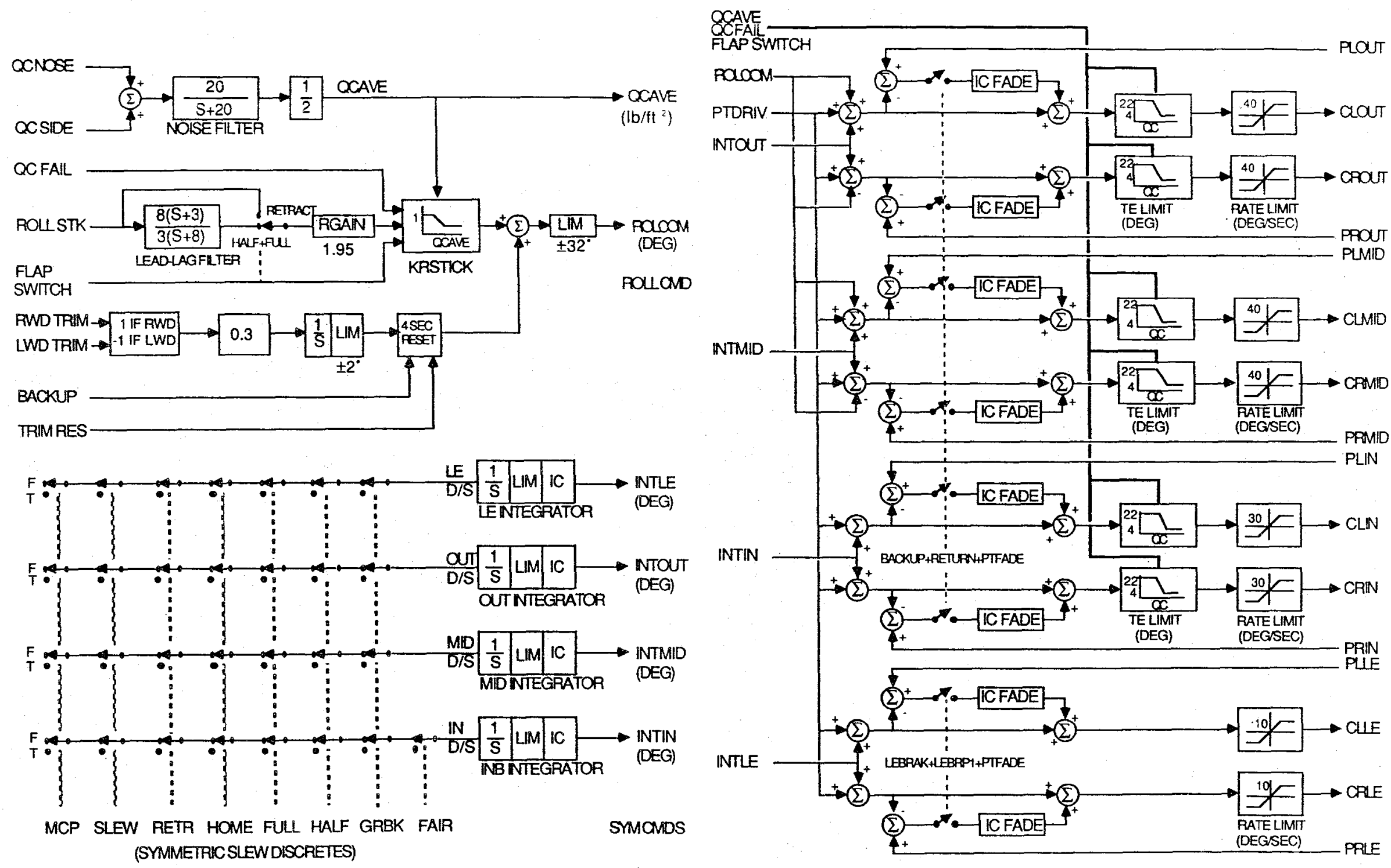

Fig. 8 Simplified block diagram of MAW commands.

Acronyms are defined in the Nomenclature section. 


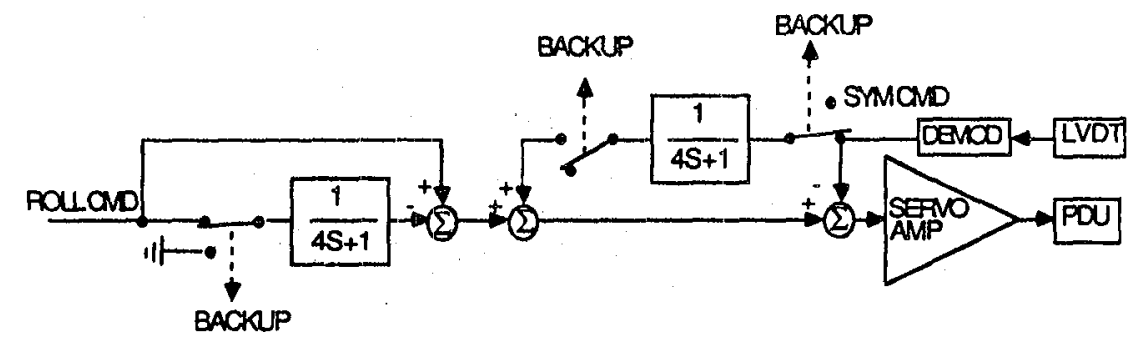

Fig. I Backup command fade-in.

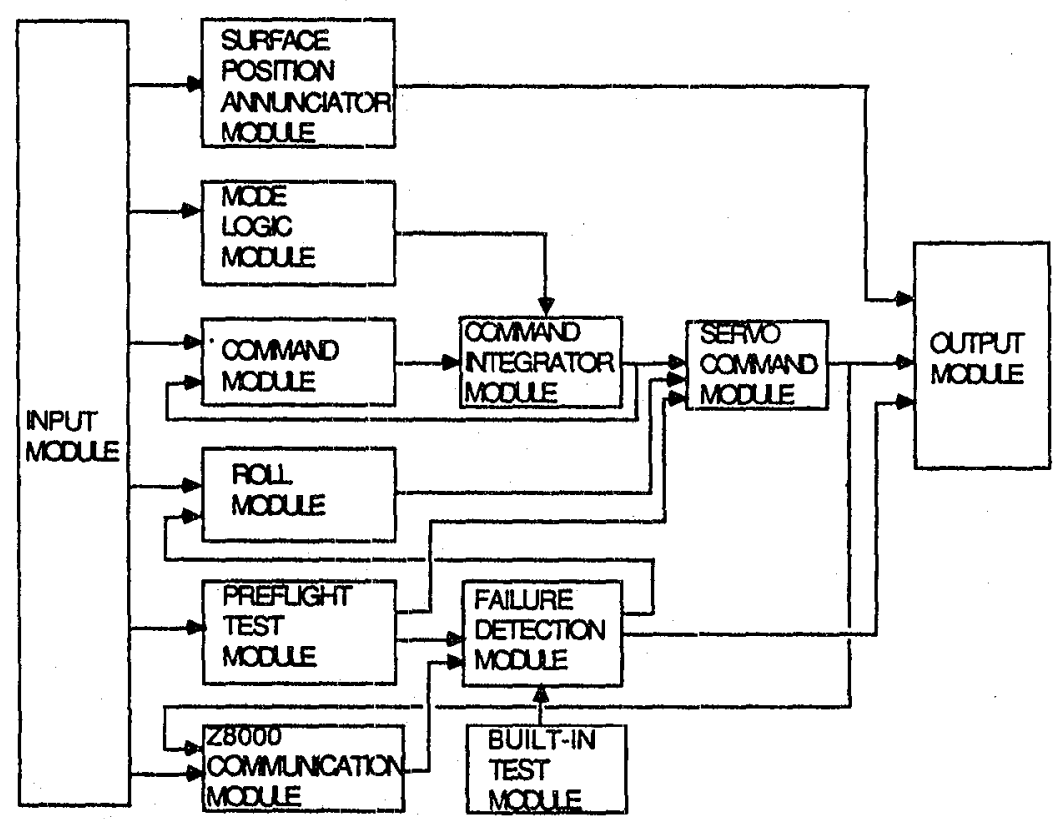

Fig. 10 software module structure.

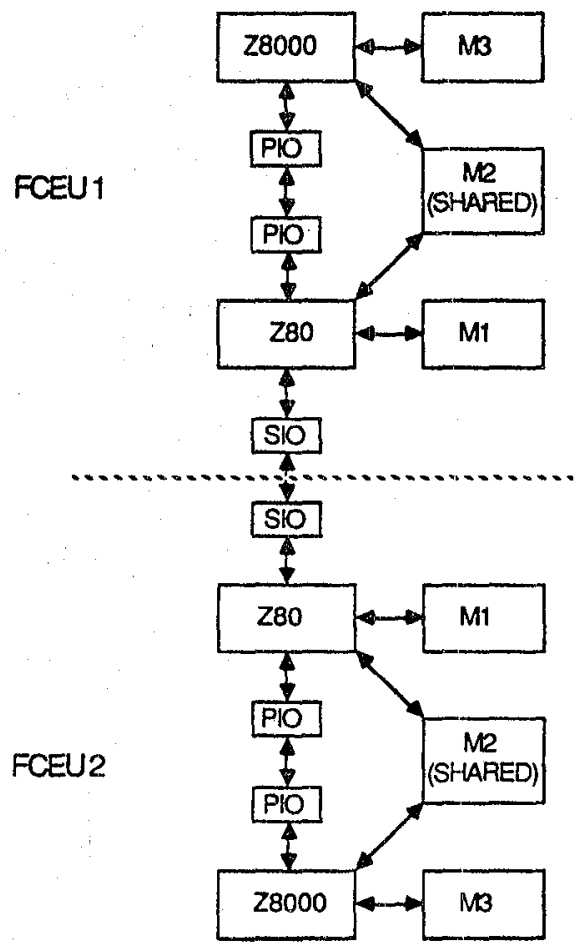

Fig. 11 FCEU communication configuration. 


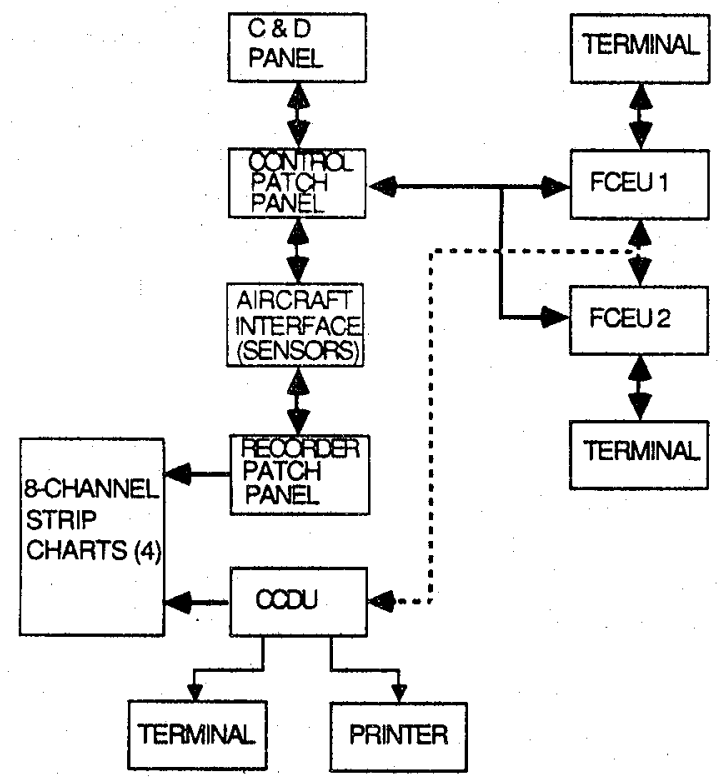

Fig. 12 Hot-bench testing setup.

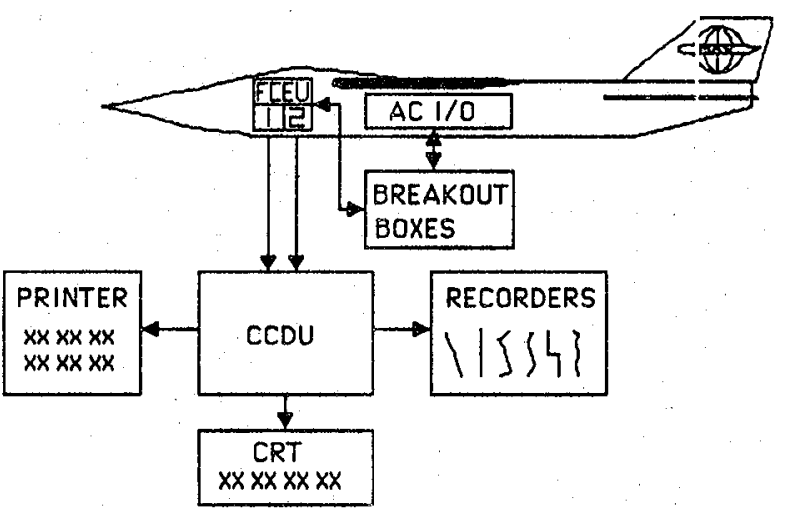

Fig. 13 Aircraft qualification testing setup. 


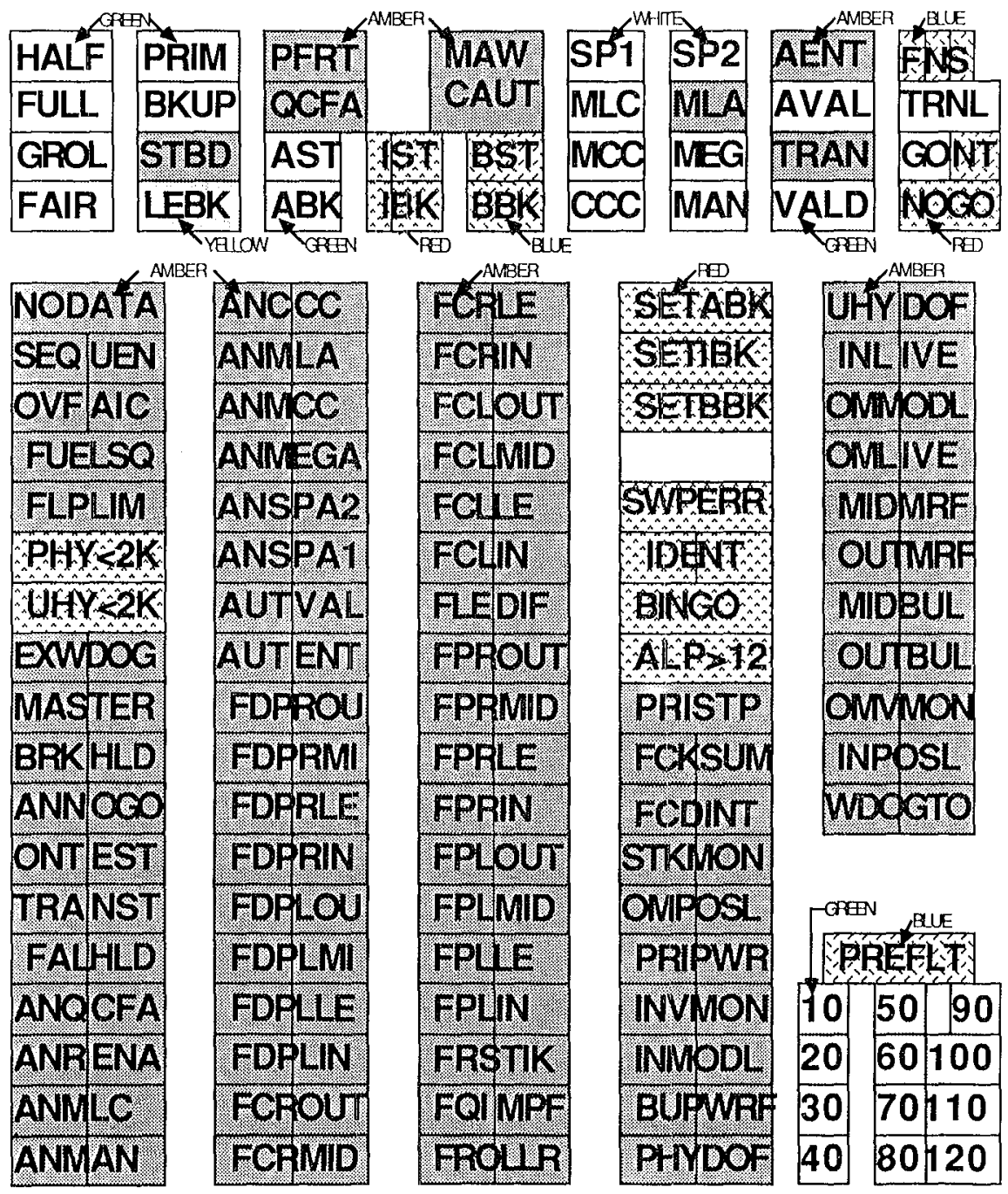

Fig. 14 MAW status and faults color panel. 


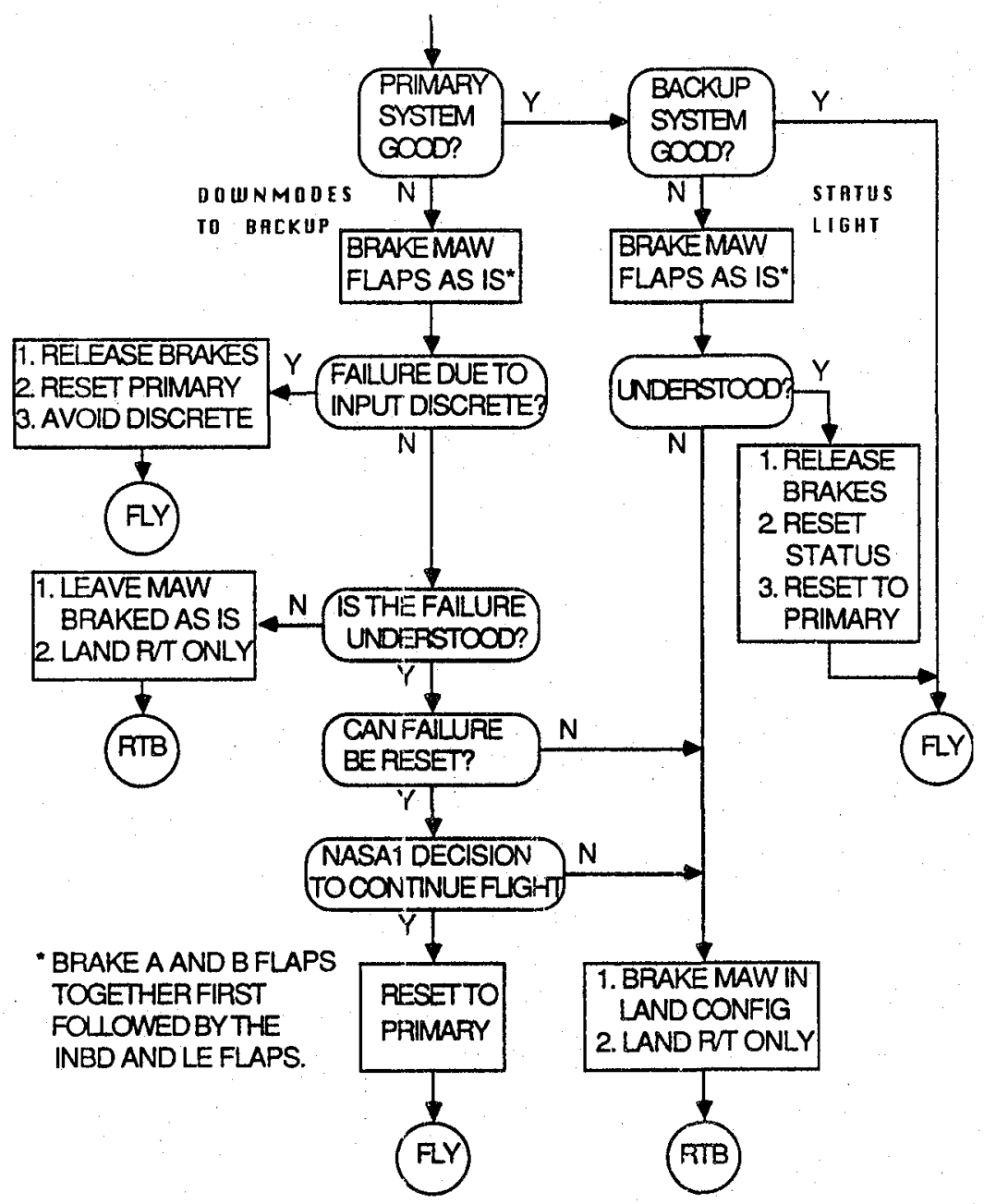

Fig. 15 MAW system failure decision tree. 


\begin{tabular}{|c|c|c|c|c|}
\hline \multicolumn{2}{|r|}{$\begin{array}{l}\text { 1. Report No. } \\
\text { NASA TM-88265 }\end{array}$} & 2. Government Accession No. & \multicolumn{2}{|c|}{ 3. Recipient's Catalog No. } \\
\hline \multirow{2}{*}{\multicolumn{3}{|c|}{$\begin{array}{l}\text { 4. Title and Subtitle } \\
\text { FLIGHT CONTROL SYSTEM DEVELOPMENT AND } \\
\text { FLIGHT TEST EXPERIENCE WITH THE F-111 } \\
\text { MISSION ADAPTIVE WING AIRCRAFT }\end{array}$}} & \multicolumn{2}{|c|}{$\begin{array}{l}\text { 5. Report Date } \\
\text { Auggust } 1986\end{array}$} \\
\hline & & & \multicolumn{2}{|c|}{ 6. Performing Organization Code } \\
\hline \multirow{2}{*}{\multicolumn{2}{|c|}{$\begin{array}{l}\text { 7. Author(s) } \\
\text { Richard R. Larsion }\end{array}$}} & & \multicolumn{2}{|c|}{$\begin{array}{l}\text { 8. Performing Organization Repore No. } \\
H-1366\end{array}$} \\
\hline & & & \multirow{2}{*}{\multicolumn{2}{|c|}{$\begin{array}{l}\text { 10. Work Unit No. } \\
\text { RTOP } 533-02-11\end{array}$}} \\
\hline \multirow{3}{*}{\multicolumn{3}{|c|}{$\begin{array}{l}\text { 9. Performing Organization Name and Address } \\
\text { NASA Ames Research Center } \\
\text { Dryden Flight Research Facility } \\
\text { P.0. Box } 273 \\
\text { Edwards, CA } 93523-5000\end{array}$}} & & \\
\hline & & & \multicolumn{2}{|c|}{ 11. Contract or Grant No. } \\
\hline & & & \multirow{2}{*}{\multicolumn{2}{|c|}{$\begin{array}{l}\text { 13. Type of Report and Period Covered } \\
\text { Technical Memorandum }\end{array}$}} \\
\hline \multirow{2}{*}{\multicolumn{3}{|c|}{$\begin{array}{l}\text { 12. Sponsoring Agency Name and Address } \\
\text { National Aeronautics and Space Administration } \\
\text { Washington, D.C. } 20546\end{array}$}} & & \\
\hline & & & \multicolumn{2}{|c|}{ 14. Sponsoring Agency Code } \\
\hline 15. & \multicolumn{4}{|c|}{$\begin{array}{l}\text { Prepared as AIAA-86-2237-CP for presentation at the AIAA Guidance, Navigation, and } \\
\text { Conference, Willfamsburg, Virginia, August } 18-20,1986 \text {. }\end{array}$} \\
\hline \multicolumn{5}{|c|}{$\begin{array}{l}\text { The wing on the NASA F-11l transonic a } \\
\text { was modified to provide flexible leading an } \\
\text { This wing is known as the mission adaptive } \\
\text { dynamic efficiency can be maintained at all } \\
\text { tional wing, the MAW has no spoilers, exter } \\
\text { to break the smooth contour. rhe leading } \\
\text { trailing edge flaps are controlled by a red } \\
\text { system that features a dual digital primary } \\
\text { viding roll and symmetric commands to the } M \\
\text { segregated analog backup system is provided } \\
\text { system failure. This paper discusses the d } \\
\text { qualification, and flight test experience o } \\
\text { backup flight control systems. }\end{array}$} \\
\hline \multicolumn{5}{|c|}{$\begin{array}{l}\text { Digital flight systems } \\
\text { Qualification testing } \\
\text { Redundancy management } \\
\text { System architecture }\end{array}$} \\
\hline 19. & $\begin{array}{l}\text { Security Classif. (of this report) } \\
\text { Unclassified }\end{array}$ & $\begin{array}{l}\text { 20. Security Classif, (of this page) } \\
\text { Unclassified }\end{array}$ & $\begin{array}{l}\text { 21. No. of Pages } \\
19\end{array}$ & $\begin{array}{l}\text { 22. Price* } \\
\text { A02 }\end{array}$ \\
\hline
\end{tabular}

"Eor sale by the National Technical Injormation Service, Springfield, Virginia 22161. 
End of Document 